\title{
Effects of Substrate Crystallographic Orientations on Microstructure in Laser Surface-Melted Single-Crystal Superalloy: Theoretical Analysis
}

\author{
Guo-Wei Wang $^{1,2} \cdot$ Jing-Jing Liang $^{1} \cdot$ Yi-Zhou Zhou $^{1} \cdot$ Tao $^{\text {Jin }}{ }^{1} \cdot$ Xiao-Feng Sun ${ }^{1} \cdot$ Zhuang-Qi Hu$^{1}$
}

Received: 22 December 2015/Revised: 3 May 2016/Published online: 9 June 2016

(C) The Chinese Society for Metals and Springer-Verlag Berlin Heidelberg 2016

\begin{abstract}
A geometric analysis technique for crystal growth and microstructure development in single-crystal welds had been previously developed. And the effect of welding conditions on the tendency of stray grains formation during solidification was researched. In the present work, these analytical methods were further extended. Combined with an original vectorization method, a 3D Rosenthal solution was used to determine thermal conditions of the welds. Afterward, the dendrite growth orientation, the dendrite growth velocity and the thermal gradient along dendrite direction were calculated and lively plotted. Finally, the tendency of stray grains formation in the solidification front was forecasted and its distribution was presented with a 3D plot. The results indicate that substrate orientation has some impacts on the crystal growth pattern, dendrite growth velocity, distribution of thermal gradient and stray grain. Based on the research methods proposed in this work, any substrate crystallographic orientation can be studied, and predicted stray grains distribution can be visualized.
\end{abstract}

KEY WORDS: Single crystal; Laser surface remelting; Weld repair; Modeling; Stray grains distribution

\section{List of symbols}

$T$

$T_{0}$

$P$

$V_{\mathrm{b}}$

$k$

$\alpha$

$G_{\mathrm{sl}}$

$G_{x}, G_{y}, G_{z}$ Component of thermal gradient along $x-, y$,

$z$-axes

Solidification temperature

Substrate temperature

Effective power

Thermal conductivity

Thermal diffusivity

Thermal gradient on solidification front
$G_{\mathrm{d}} \quad$ Component of thermal gradient along

Velocity of laser beam

Available online at http://link.springer.com/journal/40195

Yi-Zhou Zhou

yzzhou@imr.ac.cn

1 Institute of Metal Research, Chinese Academy of Sciences, Shenyang 110016, China

2 School of Materials Science and Engineering, University of Science and Technology of China, Hefei 230026, China dendrite growth direction

$V_{\mathrm{sl}} \quad$ Growth velocity of solid-liquid interface

$V_{\mathrm{d}} \quad$ Dendrite growth velocity along preferred orientation

$\theta \quad$ Angle between $G$ and $V_{\mathrm{b}}$

$\Psi \quad$ Angle between $G$ and $V_{\mathrm{d}}$

$\Phi \quad$ Areal fraction of stray grains of each point in the solidification front

\section{Introduction}

In order to improve fuel efficiency, single-crystal superalloys have been widely used $[1,2]$ in aero engines and turbine engines. Due to the complexity of casting process and large doses of precious metal usage, single-crystal superalloys are much expensive. In order to decrease the 
use of precious metals and reduce the cost, the repairing of single-crystal superalloy parts is necessary. Epitaxial laser metal forming (E-LMF), a cladding technique, can deposit a single-crystal clad onto a single-crystal substrate and is a potential technique for local repairs on single crystals [3].

During E-LMF, excessive constitutional supercooling in the weld pool may promote the nucleation and growth of equiaxed grains. Hunt [4] firstly developed an analytical model of columnar to equiaxed transition phenomenon. Following Hunt, Gaumann et al. [5] extended the model to determine the conditions under which nucleation can occur in the liquid close to a moving solid-liquid interface. Thermal gradient $(G)$ and solidification velocity $(V)$ are the key factors in the melt pool, and it is important to note that $G$ and $V$ are a strong function of position. The component of thermal gradient $G_{\mathrm{d}}$ along dendrite growth direction and the dendrite growth velocity $V_{\mathrm{d}}$ along preferred orientation are accurately described by a geometric model [6-8]. Liu and DuPont $[9,10]$ discussed the effects of melt-pool geometry on crystal growth and microstructure development in laser surface-melted superalloy single crystals and extended the analysis in Refs. [6-8]. The effects of welding conditions on stray grain formation have been researched also [11-15].

The predicting of stray grain distribution is useful for repairing single crystal. However, the past researches [6-10] are inconvenient for the prediction of complex crystal orientation. To get more accurate results, the solidification front of weld pool was divided into about $1.57 \times 10^{4}$ sections in this work. Combined with a vectorized expression of modeling proposed originally, the tendency of stray grains formation for each point in the solidification front has been calculated. Moreover, the effects of substrate crystallographic orientations on stray grain distribution in laser surface-melted single-crystal superalloy have been researched.

\section{Numerical Analysis Procedure}

\subsection{Calculations of Weld Pool Shape and Thermal Conditions}

A simple 3D Rosenthal solution [16] has been applied to define the weld pool shape and thermal conditions, and a numerical count software has been used for the computations.

Material properties, solidification temperature $T$, thermal conductivity $k$ and thermal diffusivity $\alpha$, were all based on CMSX4 superalloy from Ref. [16], where $T=1660 \mathrm{~K}$, $k=22 \mathrm{Wm}^{-1} \mathrm{~K}^{-1}$ and $\alpha=3.66 \times 10^{-6} \mathrm{~m}^{2} \mathrm{~s}^{-1}$. The temperature field is given by [17]

$$
\begin{aligned}
T= & T_{0}+\left(\frac{P}{2 \pi k \sqrt{x^{2}+y^{2}+z^{2}}}\right) \\
& \times \exp \left\{\frac{-V_{\mathrm{b}}\left(\sqrt{x^{2}+y^{2}+z^{2}}-x\right)}{2 \alpha}\right\} .
\end{aligned}
$$

In order to decrease computation, polar coordinates were used for calculating weld pool shape instead of rectangular coordinates: $x=r \cos \theta_{1} \cos \theta_{2}, y=r \cos \theta_{1} \sin \theta_{2}, z=r \sin \theta_{1}$, $-\pi / 2 \leq \theta_{1} \leq 0,0 \leq \theta_{2} \leq 2 \pi, \quad r=\left(x^{2}+y^{2}+z^{2}\right)^{0.5}$. In polar coordinates, Eq. (1) can be transformed to

$$
T=T_{0}+P /(2 \pi k r) \cdot \exp \left\{-V_{\mathrm{b}}\left[1-\cos \left(\theta_{1}\right) \cos \left(\theta_{2}\right)\right] r / 2 / \alpha\right\} .
$$

The weld pool was divided into equal segments at $\pi / 200$ intervals for both $\theta_{1}$ and $\theta_{2}$. The weld pool shape was defined and drawn by calculating Eq. (2). The width $W$, length $L$ and height $H$ of the weld pool were determined as $y_{\max }-y_{\min }, x_{\max }-x_{\min }$ and $0-z_{\min }$, respectively.

Figure 1 shows the schematic diagram of the weld pool. The laser beam moved in the negative $x$ direction, and $z$ axis is perpendicular to the sample surface. Projected onto the $y-z$ plane, the solidification region was divided into 200 and 100 equal segments along the width $(y)$ and height $(z)$ directions of the pool, respectively. Grid points out of the cross section of the weld pool were discarded. The solidification region was divided into about $1.57 \times 10^{4}$ sections. Then, the thermal gradient, solidification velocity and stray grain areal fraction at each grid point were calculated as follows:

$G_{x}=\partial T / \partial x, G_{y}=\partial T / \partial y, G_{z}=\partial T / \partial z$.

Combined with Eq. (1), Eq. (3) can be calculated with software.

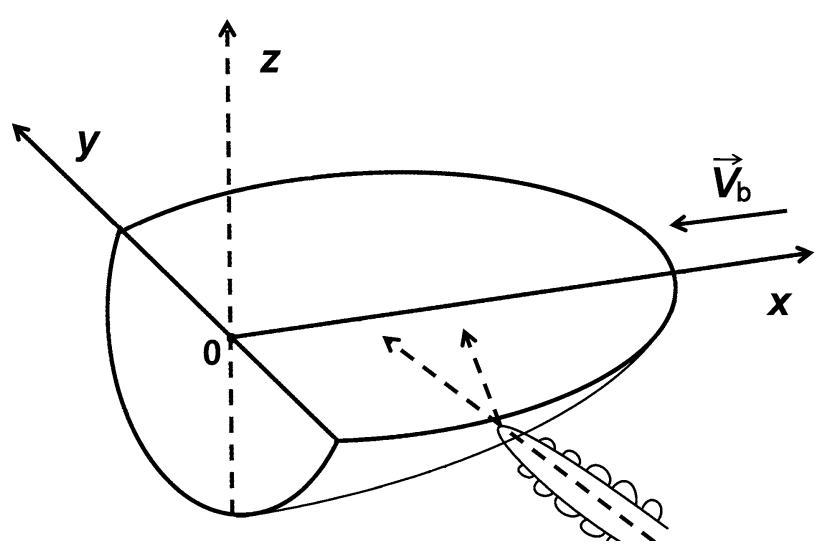

Fig. 1 Schematic diagram of weld pool; heat source is located at $x=y=z=0$ 
$G_{\mathrm{s} 1}=\left(G_{x}^{2}+G_{y}^{2}+G_{z}^{2}\right)^{0.5}$.

The relation between $V_{\mathrm{sl}}$ and $V_{\mathrm{b}}$ is explained in Eq. (5) [6-8],

$V_{\mathrm{s} 1}=V_{\mathrm{b}} \cos \theta=V_{\mathrm{b}}\left|G_{x}\right| / G_{\mathrm{s} 1}$.

Based on Eqs. (1)-(5), thermal gradient on solidification front $G_{\mathrm{s} 1}$ and growth velocity of solid-liquid interface $V_{\mathrm{sl}}$ of each section in the weld pool were calculated.

\subsection{Calculation of Dendrite Growth Direction, $G_{\mathrm{d}}$ and $V_{\mathrm{d}}$}

At any given location on the solidification front, one of the six variants of the best set of the $<001>$ easy growth directions ([100], [010], [001], [100], [010], [001] ) will be best aligned with the solidification front normal, and this will be the active dendrite growth direction at specific location $[6-8,10]$. Previous studies $[6-8,10]$ have shown computing methods for $G_{\mathrm{d}}$ and $V_{\mathrm{d}}$, but it is inconvenient to calculate tens of thousands of points on the solidification front. For the convenience of computing programming and dealing with a large amount of computations, this work has developed a new algorithm to handle complex computations for cubic alloys. The coordinate used for the following calculation resides in the crystal orientation of the substrate. The laser beam moved in the crystal orientation $\left[\bar{h}_{1} \bar{k}_{1} \bar{l}_{1}\right]$ on the surface of $\left(h_{3} k_{3} l_{3}\right)$. The crystal orientation along $x$-, $y$ - and $z$-axes can be set as $\left[h_{1} k_{1} l_{1}\right],\left[h_{2} k_{2} l_{2}\right]$ and $\left[\begin{array}{lll}h_{3} & k_{3} & l_{3}\end{array}\right]$, respectively.

The $\left[h_{2} k_{2} l_{2}\right]$ are determined by the cross product of $\left[h_{1}\right.$ $\left.k_{1} l_{1}\right]$ and $\left[\begin{array}{lll}h_{3} & k_{3} & l_{3}\end{array}\right]$ :

$\left[\begin{array}{lll}h_{2} & k_{2} & l_{2}\end{array}\right]=\left[\begin{array}{lll}h_{3} & k_{3} & l_{3}\end{array}\right] \times\left[\begin{array}{lll}h_{1} & k_{1} & l_{1}\end{array}\right]$.

The vectorization algorithm for $G_{x}, G_{y}, G_{z}$ :

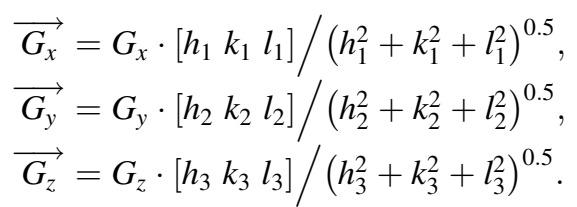

The calculation of $G_{100}, G_{010}, G_{001}$ :

$G_{100}=\overrightarrow{G_{x}} \cdot\left[\begin{array}{lll}1 & 0 & 0\end{array}\right]+\overrightarrow{G_{y}} \cdot\left[\begin{array}{lll}1 & 0 & 0\end{array}\right]+\overrightarrow{G_{z}} \cdot\left[\begin{array}{lll}1 & 0 & 0\end{array}\right]$,

$G_{010}=\overrightarrow{G_{x}} \cdot\left[\begin{array}{lll}0 & 1 & 0\end{array}\right]+\overrightarrow{G_{y}} \cdot\left[\begin{array}{lll}0 & 1 & 0\end{array}\right]+\overrightarrow{G_{z}} \cdot\left[\begin{array}{lll}0 & 1 & 0\end{array}\right]$,

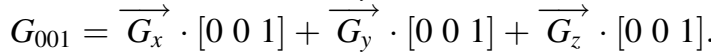

If $\left|G_{100}\right|>\left|G_{010}\right|$ and $\left|G_{100}\right|>\left|G_{001}\right|, G_{\mathrm{d}}=\left|G_{100}\right|$. If $G_{100}>0$, the dendrite grows along [100] direction, else along $[\overline{1} 00]$.

If $\left|G_{010}\right|>\left|G_{100}\right|$ and $\left|G_{010}\right|>\left|G_{001}\right|, G_{\mathrm{d}}=\left|G_{010}\right|$. If $G_{010}>0$, the dendrite grows along [010] direction, else along $[0 \overline{1} 0]$.
If $\left|G_{001}\right|>\left|G_{010}\right|$ and $\left|G_{001}\right|>\left|G_{100}\right|, G_{\mathrm{d}}=\left|G_{001}\right|$. If $G_{001}>0$, the dendrite grows along [001] direction, else along $[00 \overline{1}]$.

Using Eqs. (1)-(3), (6)-(8), component of thermal gradient along dendrite growth direction of each section was calculated.

The dendrite tip velocity has given by Refs. [5-7, 12], $G_{x} / G_{\mathrm{sl}}=V_{\mathrm{sl}} / V_{\mathrm{b}}=\cos \theta, G_{\mathrm{d}} / G_{\mathrm{sl}}=V_{\mathrm{sl}} / V_{\mathrm{d}}=\cos \Psi$, so,

$V_{\mathrm{d}}=V_{\mathrm{b}} \cdot\left|G_{x}\right| / G_{\mathrm{d}}$.

Using Eqs. (1)-(3), (6)-(9), dendrite growth velocity along the preferred orientation of each section was calculated.

\subsection{Calculation of Areal Fraction of Stray Grains}

In this work, constants of $a, N_{0}$ and $n$ for CMSX-4 came from Ref. [16], $a=1.25 \times 10^{6} \mathrm{~s} \mathrm{~K}^{3.4} \mathrm{~m}^{-1}, n=3.4$ and $N_{0}=2 \times 10^{15} \mathrm{~m}^{-3}$. The expression [16] was solved for $\Phi$ as a function of $G$ and $V$, yielding

$$
\begin{aligned}
G & =G_{\mathrm{d}}, V=V_{\mathrm{d}}, S=\frac{-4 \pi N_{0}}{3}\left\{\frac{1}{(n+1)\left(G^{n} / a V\right)^{1 / n}}\right\}^{3} \\
& =-2.356 \times 10^{19}\left(\frac{V^{3 / 3.4}}{G^{3}}\right), \Phi=1-\mathrm{e}^{S} .
\end{aligned}
$$

The above equations were used for calculating stray grains areal fraction $\Phi$ of each section of weld pool (the weld pool was divided into numerous sections in 2.1).

\section{Results}

\subsection{Weld Pool Shape and Thermal Conditions}

The same effective power $(P=100 \mathrm{~W})$, velocity of laser beam $\left(V_{\mathrm{b}}=0.01 \mathrm{~m} / \mathrm{s}\right)$ and substrate temperature $\left(T_{0}=300 \mathrm{~K}\right)$ are used in this paper, and it is worth mentioning that the effective power is less than the laser power.

Figure 2a shows the computation result of weld pool shape calculated by Eq. (2). Projections are used for figures in this work. The calculated values of weld pool width, length and height are as follows: $W=7.114 \times 10^{-4} \mathrm{~m}$, $L=7.928 \times 10^{-4} \mathrm{~m}, \quad H=3.557 \times 10^{-4} \mathrm{~m} . \quad$ It $\quad$ is observed that the weld pool shape is nearly domed.

To better explain the model, the calculation result of one grid point, noted as B (from Sect. 2.1), is chosen as an example. This point $\left(x=3.2850 \times 10^{-4}, y=2.4009 \times\right.$ $\left.10^{-4}, z=-1.9305 \times 10^{-4}\right)$ is one of the points in the solidification front. By calculating Eqs. (3)-(5), we can obtain the following parameters for point $\mathrm{B}, G_{x \mathrm{~B}}=$ $G_{x}=-1.7000 \times 10^{6} \mathrm{~K} / \mathrm{m}, \quad G_{y \mathrm{~B}}=-2.6004 \times 10^{6} \mathrm{~K} / \mathrm{m}$, 

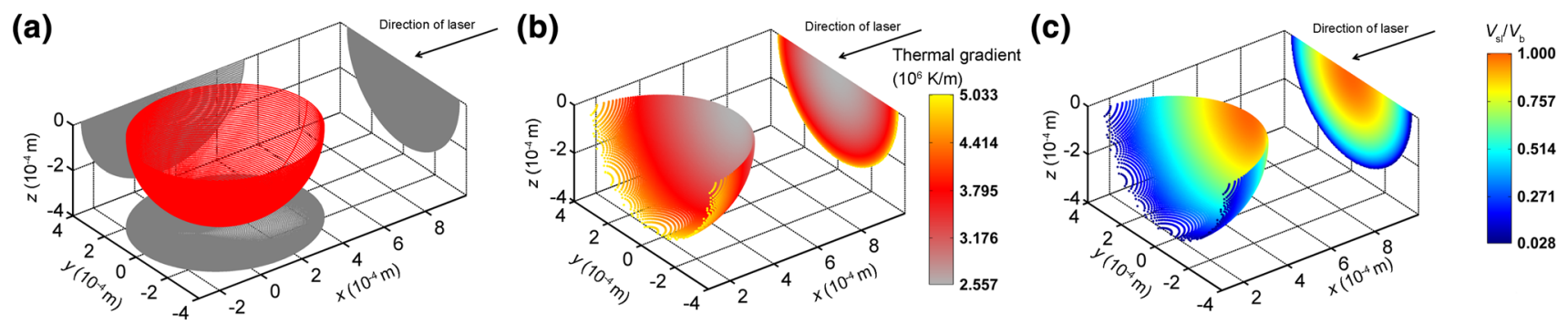

Fig. 2 Weld pool shape and thermal conditions for $P=100 \mathrm{~W}, V_{\mathrm{b}}=0.01 \mathrm{~m} / \mathrm{s}, T_{0}=300 \mathrm{~K}$ : a weld pool shape; b thermal gradient on solidification front $G_{\mathrm{sl}}$; c growth velocity of solid-liquid interface $V_{\mathrm{sl}} / V_{\mathrm{b}}$

$G_{z \mathrm{~B}}=2.0908 \times 10^{6} \mathrm{~K} / \mathrm{m}, \quad G_{\mathrm{s} 1 \mathrm{~B}}=3.7448 \times 10^{6} \mathrm{~K} / \mathrm{m}$, $V_{\mathrm{s} 1 \mathrm{~B}} / V_{\mathrm{b}}=0.4540$.

Each grid point has been calculated as B. The calculated thermal gradient on solidification front $G_{\mathrm{sl}}$ is graphically shown in Fig. 2b. It can be seen that, in the increasing $x$ direction, $G_{\mathrm{sl}}$ decreases fast at first and then slowly. From Fig. $2 \mathrm{~b},\left(G_{\mathrm{sl}}\right)_{\max }=5.082 \times 10^{6} \mathrm{~K} / \mathrm{m},\left(G_{\mathrm{sl}}\right)_{\min }=2.557 \times$ $10^{6} \mathrm{~K} / \mathrm{m}$. In Fig. 2c, as $x$ increases, growth velocity of solid-liquid interface $V_{\mathrm{sl}}$ increases slowly and then fast. The results in Fig. 2c also display that $\left(V_{\mathrm{sl}}\right)_{\max }=V_{\mathrm{b}}$, $\min \left(V_{\mathrm{sl}}\right)_{\min }=0.013 V_{\mathrm{b}}$. In a mathematical sense, $\left(V_{\mathrm{sl}}\right)$ $\min =0$. However, the number of points used in the numerical computing is insufficient to set $V_{\mathrm{sl}}$ close to 0 .

With the calculated results of $W$ and $H$, the grid points are generated (Sect. 2.1) and the values of $G_{\mathrm{sl}}$ and $V_{\mathrm{sl}}$ will be used to calculate dendrite growth direction, $G_{\mathrm{d}}$ and $V_{\mathrm{d}}$.

\subsection{Dendrite Growth Direction}

For simplicity, $[100] /(001)$ denotes that laser scans in the [100] direction on the (001) plane. Dendrite growth of six orientations is predicted based on Sect. 2.2.

This calculation process is explained by taking [100]/ (001) as an example. In this case, $x$ - and $z$-axes are $[\overline{100}]$ and [001] directions, respectively. From Eq. (6), $\left[\bar{h}_{1} \bar{k}_{1} \bar{l}_{1}\right]=[100],\left[h_{1} k_{1} l_{1}\right]=\left[\begin{array}{lll}-1 & 0 & 0\end{array}\right],\left[h_{3} k_{3} l_{3}\right]=\left[\begin{array}{lll}0 & 0 & 1\end{array}\right]$, $\left[\begin{array}{lll}h_{2} & k_{2} & l_{2}\end{array}\right]=\left[\begin{array}{lll}h_{3} & k_{3} & l_{3}\end{array}\right] \times\left[\begin{array}{lll}h_{1} & k_{1} & l_{1}\end{array}\right]=\left[\begin{array}{lll}0 & -1 & 0\end{array}\right]$. Therefore, $y$-axis is [010] direction. From Eq. (7) and Sect. 3.1, for

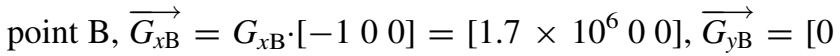
$\left.2.6004 \times 10^{6} 0\right], \overrightarrow{G_{z \mathrm{~B}}}=\left[\begin{array}{lll}0 & 0 & 2.0908 \times 10^{6}\end{array}\right], \quad G_{100 \mathrm{~B}}=$ $1.7000 \times 10^{6} \mathrm{~K} / \mathrm{m}, G_{010 \mathrm{~B}}=2.6004 \times 10^{6} \mathrm{~K} / \mathrm{m}, G_{001 \mathrm{~B}}=$ $2.0908 \times 10^{6} \mathrm{~K} / \mathrm{m}$. As analyzed in Sect. 2.2, $\left|G_{010 \mathrm{~B}}\right|>$ $\left|G_{100 \mathrm{~B}}\right|$ and $\left|G_{010 \mathrm{~B}}\right|>\left|G_{001 \mathrm{~B}}\right|$, so the dendrite grows along [010] or [010]. Because $G_{010 \mathrm{~B}}=2.6004 \times 10^{6}>0$, the dendrite in point $\mathrm{B}$ grows along [010] in the direction of negative $y$-axis (Fig. 3a).

Dendrite growth direction of each point for different orientations has been calculated as the methods explained before, and the results are presented in Fig. 3. From Fig. 3, it can be concluded that part of dendrites growth direction will change when laser scanning direction or substrate crystallographic orientation changes even though the thermal conditions remain constant. It is worth noting that stray grain formation is ignored in this part.

The area fractions of dendrites growth direction for different orientations are given in Table 1. From Table 1 and Fig. 3, it is known that as laser direction changes, the area of the [010] dendrite increases while that of $[0 \overline{10}]$

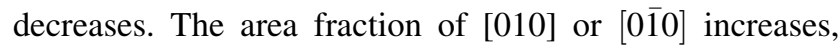
[100] or [100] decreases, and [001] or [001] keeps stable. Compared with Fig. 3a, d, the area of dendrites growing along [010] increases while along [010] disappears.

Figure $3 \mathrm{e}$ and $\mathrm{f}$ is much different from other orientations. In Fig. 3e, the dendrites along [001] originate from the bottom of the weld pool and end at its surface. Compared with other figures, the largest difference is that most of the dendrites grow along [100] or [010] and few dendrite grows along [001] in Fig. 3f.

\subsection{Distribution of $G$ Along Dendrite}

Figure 4 shows the calculated $G_{\mathrm{d}}$ of each point for different orientations and the plotted distribution of $G_{\mathrm{d}}$. In the same position and thermal conditions of the weld pool, $G_{\mathrm{d}}$, $\left(G_{\mathrm{d}}\right)_{\min }$ and $\left(G_{\mathrm{d}}\right)_{\max }$ may change when laser scanning direction or substrate orientation changes. Compared with Fig. 2, the distribution of $G_{\mathrm{d}}$ is different from the distribution of $G_{\mathrm{sl}}$. Both $G_{\mathrm{d}}$ and $G_{\mathrm{sl}}$ reach their maximum value when $x$ is minimum. The $\left(G_{\mathrm{d}}\right)_{\min }$ in Fig. 4 is smaller than the $\left(G_{\mathrm{s} 1}\right)_{\min }$ in Fig. 2 apparently. The $\left(G_{\mathrm{d}}\right)_{\max }$ in Fig. 4 is close to the $\left(G_{\mathrm{sl}}\right)_{\max }$ except Fig. 4f. It is interesting to mention that both $\left(G_{\mathrm{d}}\right)_{\min }$ and $\left(G_{\mathrm{d}}\right)_{\max }$ in Fig. $4 \mathrm{f}$ are significantly smaller than other orientations in Fig. 4.

Combined Fig. 4 with Fig. 3, it is easy to see that the converging boundary of different growth direction dendrites is the favorable location for smaller $G_{\mathrm{d}}$ except for the converging boundary of the dendrites going along [100] and $[0 \overline{1} 1]$ in Fig. $3 b$.

The area fraction of different components of thermal gradient along dendrite growth direction $G_{\mathrm{d}}$ for different 
(a)

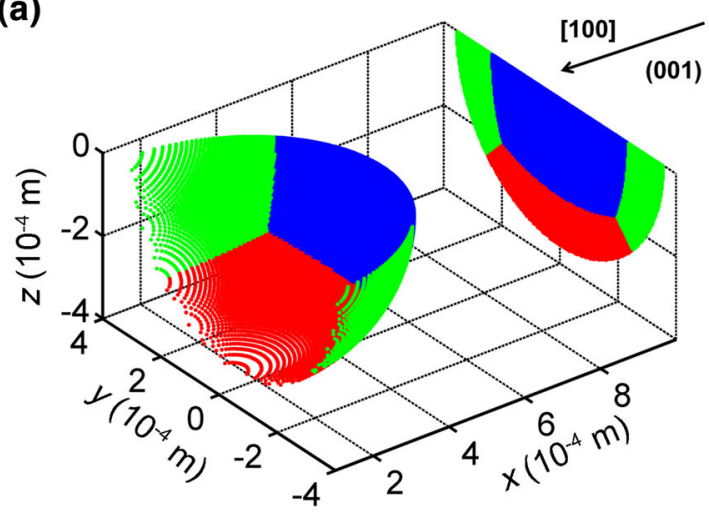

(c)

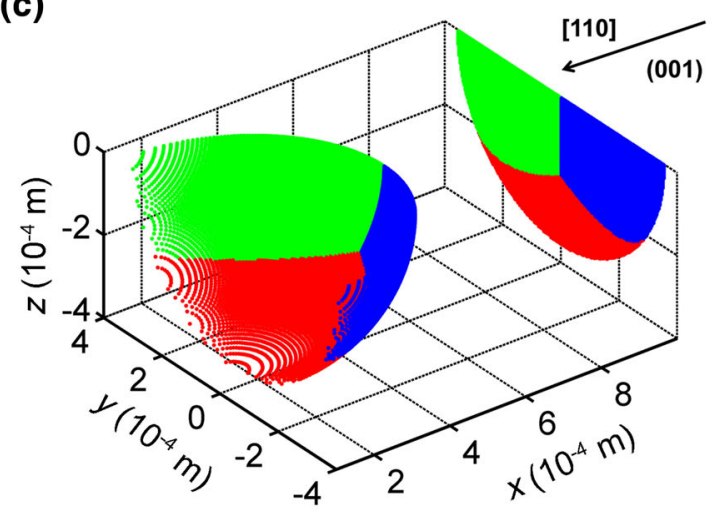

(e)

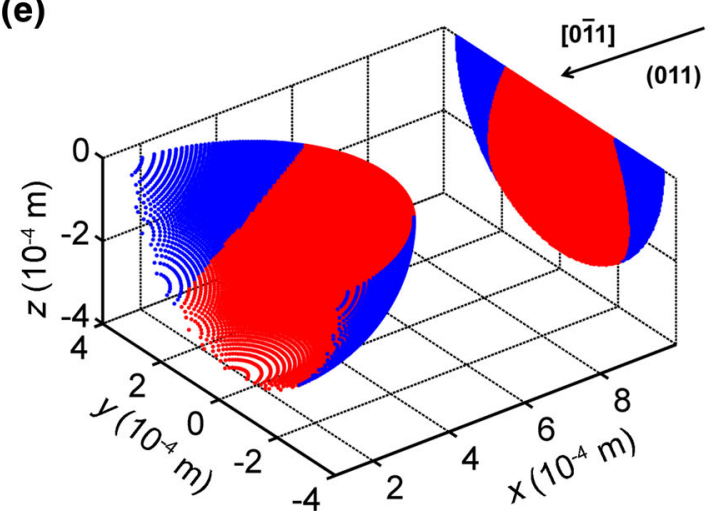

(b)
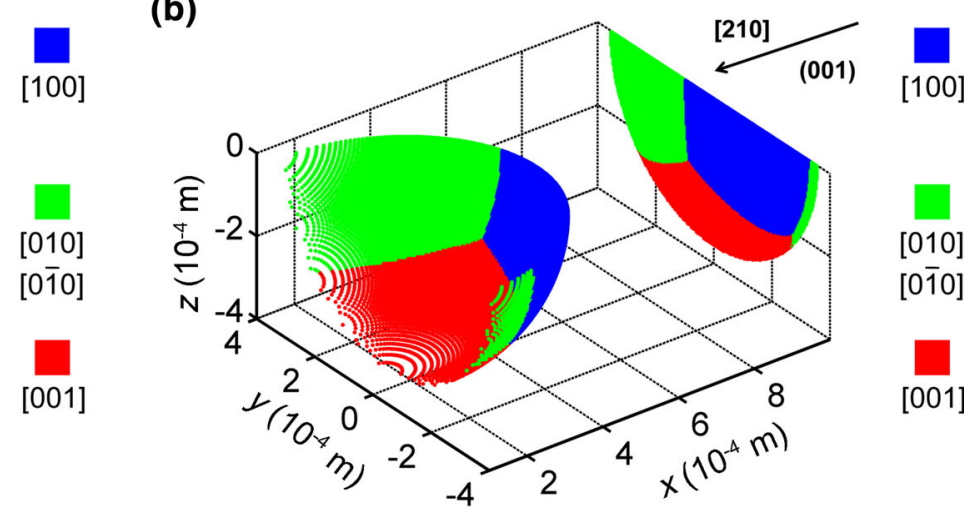

(d)
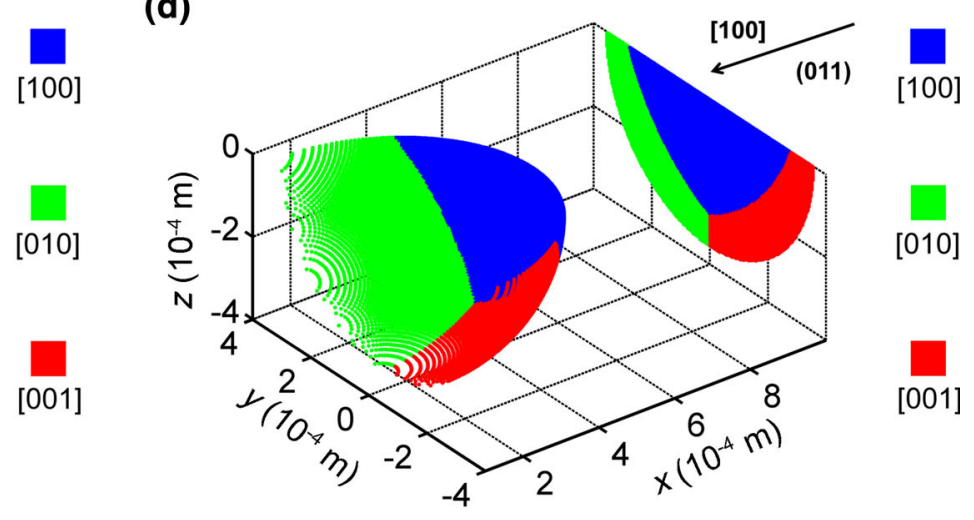

(f)
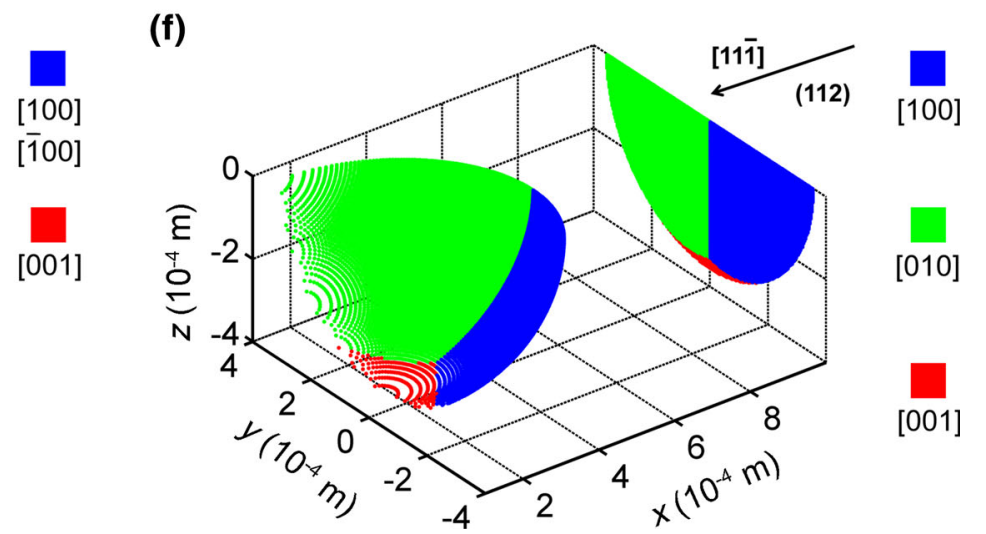

Fig. 3 Calculated dendrite growth direction for various orientations: a [100]/(001); b [210]/(001); c $[110] /(001) ; \mathbf{d}[100] /(011) ; \mathbf{e}[0 \overline{1} 1] /(011)$; f $[11 \overline{1}] /(112)$

Table 1 Area fraction of dendrites growth direction in the cross section

\begin{tabular}{lllllrr}
\hline & {$[100] /(001)(\%)$} & {$[210] /(001)(\%)$} & {$[110] /(001)(\%)$} & {$[100] /(011)(\%)$} & {$[0 \overline{1} 1] /(011)(\%)$} & {$[11 \overline{1}] /(112)(\%)$} \\
\hline$[100]$ or $[\overline{1} 00]$ & 48.95 & 45.43 & 37.75 & 48.92 & 24.51 & 49.17 \\
{$[010]$ or $[0 \overline{1} 0]$} & 25.63 & 29.61 & 37.75 & 25.54 & 0.00 & 49.17 \\
{$[001]$ or $[00 \overline{1}]$} & 25.42 & 24.95 & 24.51 & 25.54 & 75.49 & 1.67 \\
\hline
\end{tabular}

orientations is given in Table 2. In the conditions of [100]/ (001) and $[100] /(011)$, the area fraction of $G_{\mathrm{d}} \leq 2 \times 10^{6}$ is apparently smaller than other conditions. The area fraction of $G_{\mathrm{d}}>3 \times 10^{6}$ in $[11 \overline{1}] /(112)$ is larger than other conditions. Combined with the previous analysis, it can be concluded that the orientations have an impact on the 
(a)

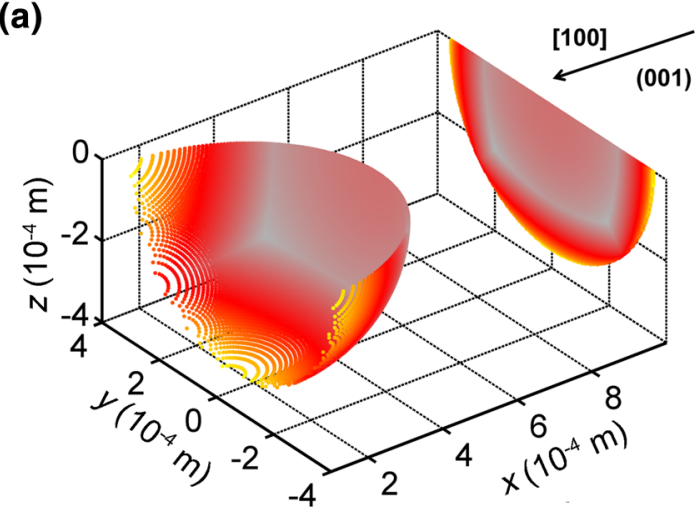

(c)

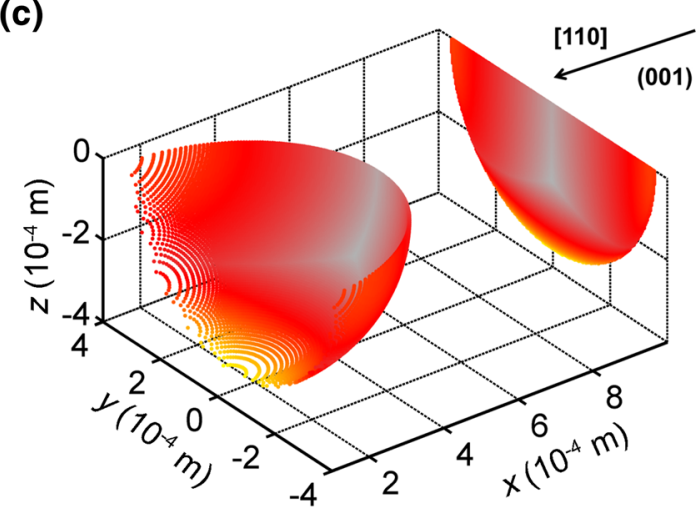

(e)

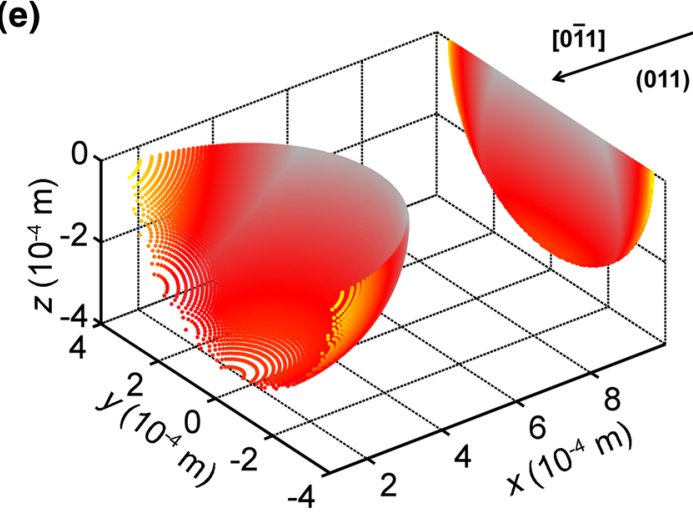

(b)
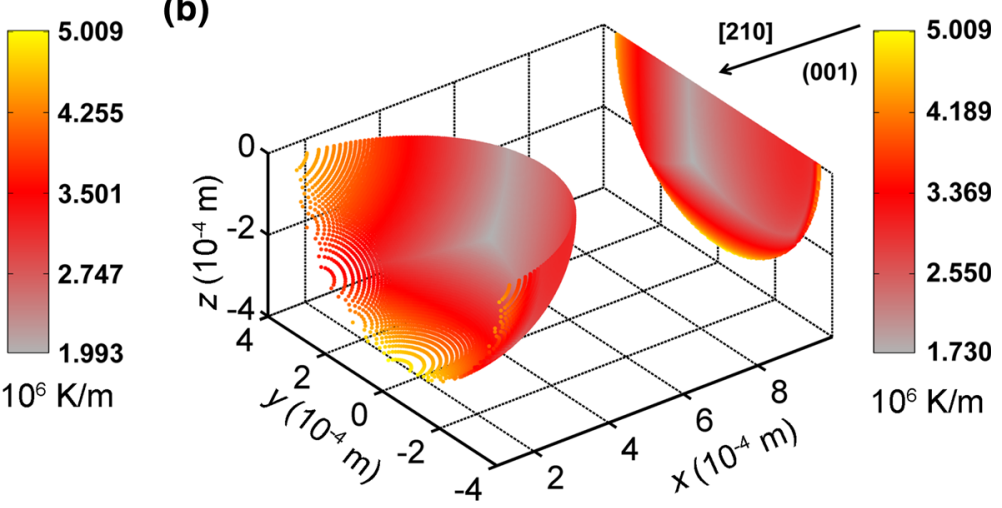

(d)
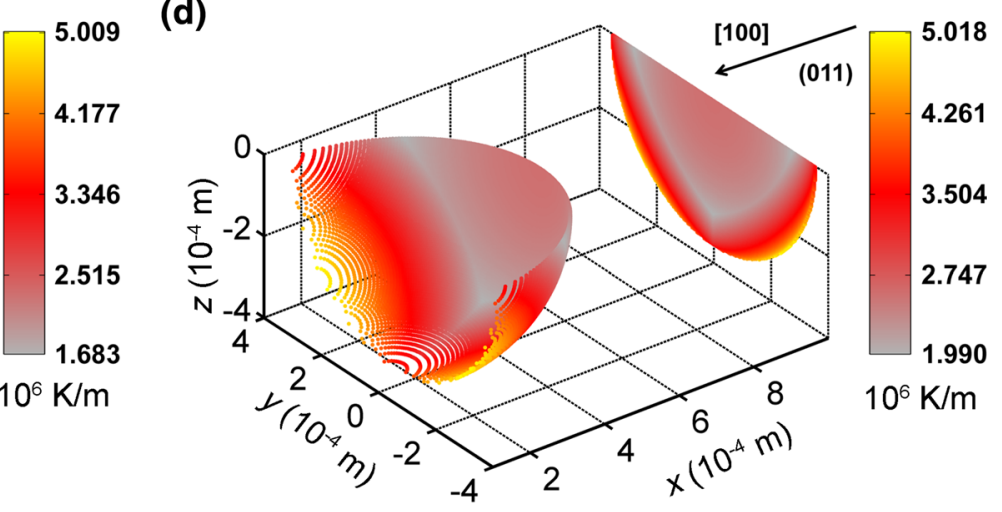

(f)

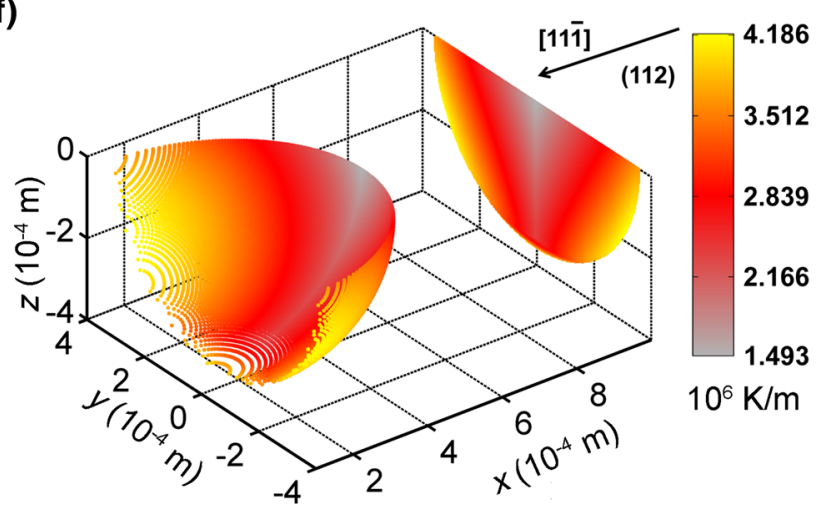

Fig. 4 Calculated component of thermal gradient along dendrite growth direction $G_{\mathrm{d}}$ for various orientations: a $[100] /(001) ; \mathbf{b}[210] /(001) ; \mathbf{c}$ $[110] /(001) ; \mathbf{d}[100] /(011) ; \mathbf{e}[0 \overline{1} 1] /(011) ; \mathbf{f}[11 \overline{1}] /(112)$

Table 2 Area fraction in the cross section of $G_{\mathrm{d}}$

\begin{tabular}{lccccrr}
\hline & {$[100] /(001)(\%)$} & {$[210] /(001)(\%)$} & {$[110] /(001)(\%)$} & {$[100] /(011)(\%)$} & {$[0 \overline{1} 1] /(011)(\%)$} & {$[11 \overline{1}] /(112)(\%)$} \\
\hline$G_{\mathrm{d}} \leq 2 \times 10^{6}$ & 0.05 & 7.04 & 9.16 & 0.03 & 9.16 & 7.45 \\
$2 \times 10^{6}<G_{\mathrm{d}} \leq 3 \times 10^{6}$ & 75.07 & 66.27 & 53.46 & 75.20 & 53.46 & 48.22 \\
$3 \times 10^{6}<G_{\mathrm{d}} \leq 4 \times 10^{6}$ & 19.45 & 22.22 & 34.67 & 19.45 & 34.67 & 41.55 \\
$G_{\mathrm{d}}>4 \times 10^{6}$ & 5.43 & 4.47 & 2.71 & 5.32 & 2.71 & 2.78 \\
\hline
\end{tabular}


distribution and areal fraction of $G_{\mathrm{d}}$. From Eq. (9), combined with $G_{\mathrm{d}}, G_{x}$ and $V_{\mathrm{b}}$, the dendrites growth velocity can be calculated.

\subsection{Distribution of Dendrites Growth Velocity}

Figure 5a shows the computational results of $[100] /(001)$. From Eq. (9), Sects. 3.1 and 3.2, for point B, $V_{\mathrm{dB}} /$ $V_{\mathrm{b}}=0.654, \quad$ for $\quad V_{\mathrm{dB}}=V_{\mathrm{b}} \times\left|G_{x}\right| / G_{\mathrm{d}}=V_{\mathrm{bB}} \times\left|G_{x \mathrm{~B}}\right| /$ $G_{\mathrm{dB}}=V_{\mathrm{b}} \times 1.7 \times 10^{6} /\left(2.6004 \times 10^{6}\right)=0.654 V_{\mathrm{b}}$.

In Fig. $5, V_{\mathrm{d}}$ of each point for different orientations has been calculated and the distribution of $V_{\mathrm{d}}$ has been plotted.

(a)

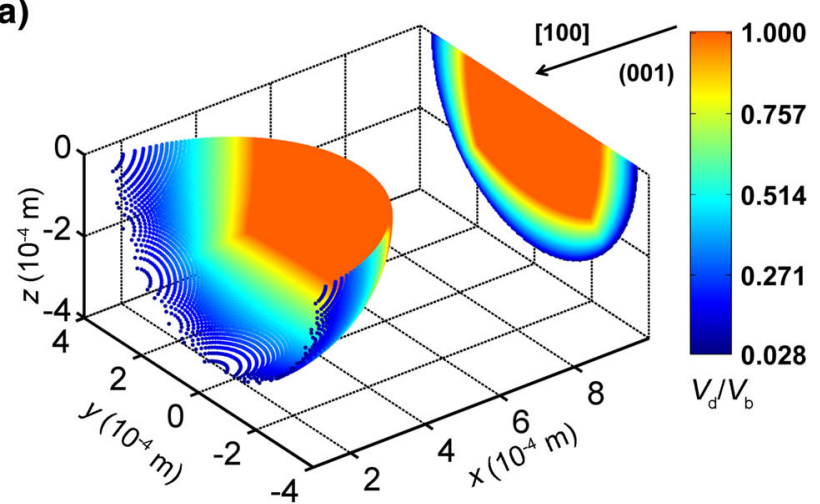

(c)

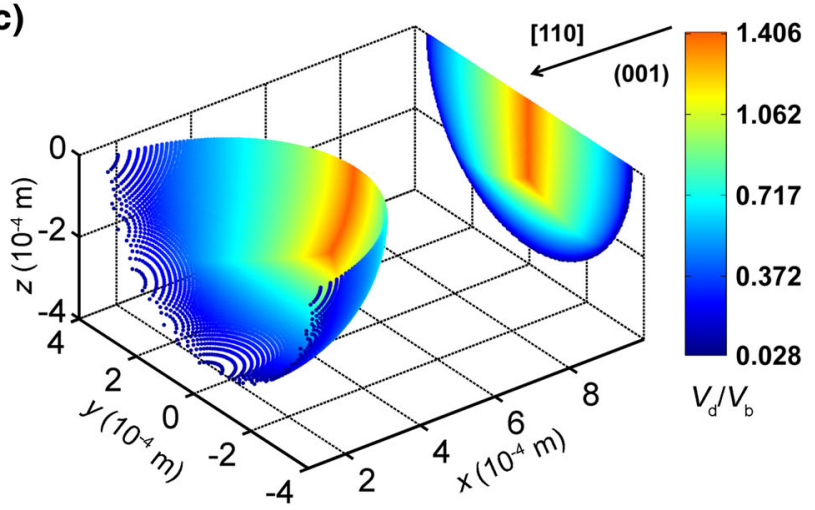

(e)

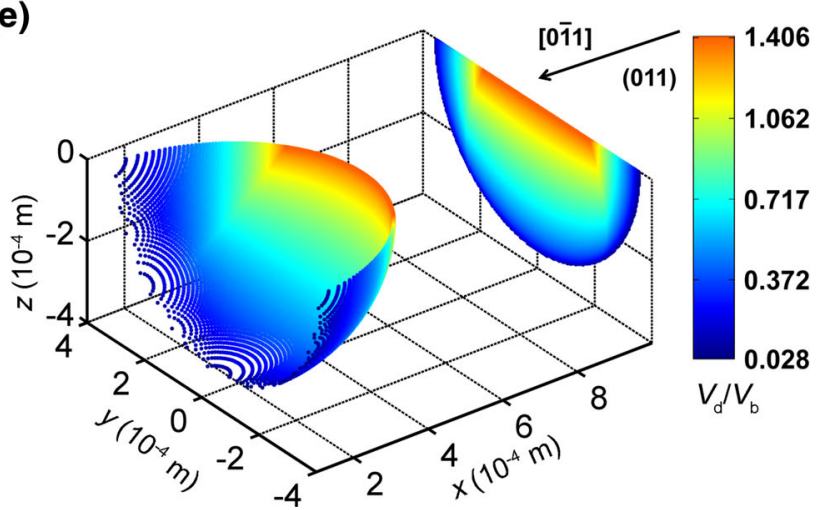

It is seen that the values of $V_{\mathrm{b}}$ are different due to the difference in orientation even though in the same position and thermal conditions. With the increasing $x$ value, $V_{\mathrm{d}}$ increases except Fig. 5b. The $\left(V_{\mathrm{d}}\right)_{\max }$ is equal to $V_{\mathrm{b}}$ in Fig. 5a and d. Obviously, the $\left(V_{\mathrm{d}}\right)_{\max }$ is larger than $V_{\mathrm{b}}$ in Fig. 5b-f. It is worth noting that the $\left(V_{\mathrm{d}}\right)_{\max }=1.72 V_{\mathrm{b}}$ in Fig. $5 \mathrm{f}$ is apparently bigger than that in others.

The area fraction of different dendrite growth velocities along the preferred orientation $V_{\mathrm{d}}$ for different orientations is given in Table 3. In $[100] /(001)$ and $[100] /(011)$, the maximum of $V_{\mathrm{d}} / V_{\mathrm{b}}$ is equal to 1 . In conclusion, the distribution and area fraction of $V_{\mathrm{d}}$ change when the (b)

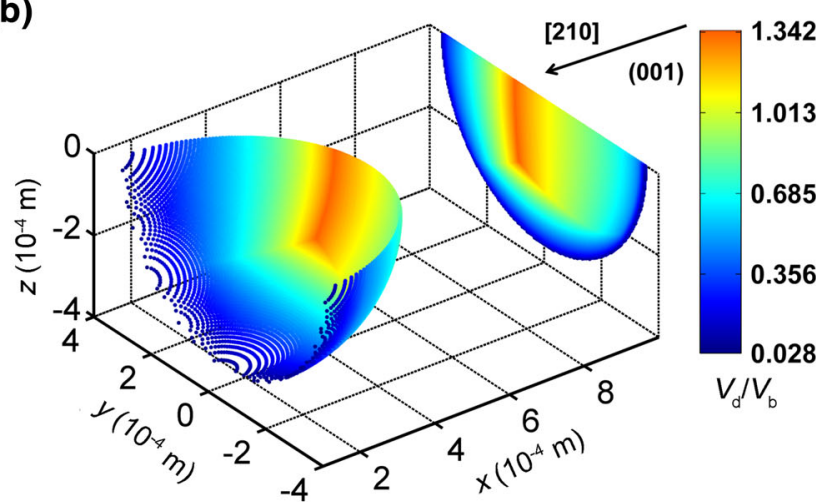

(d)

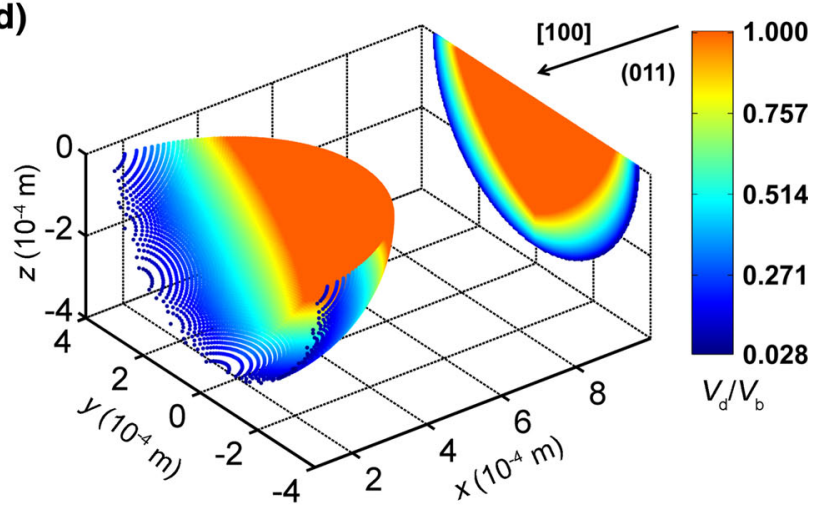

(f)

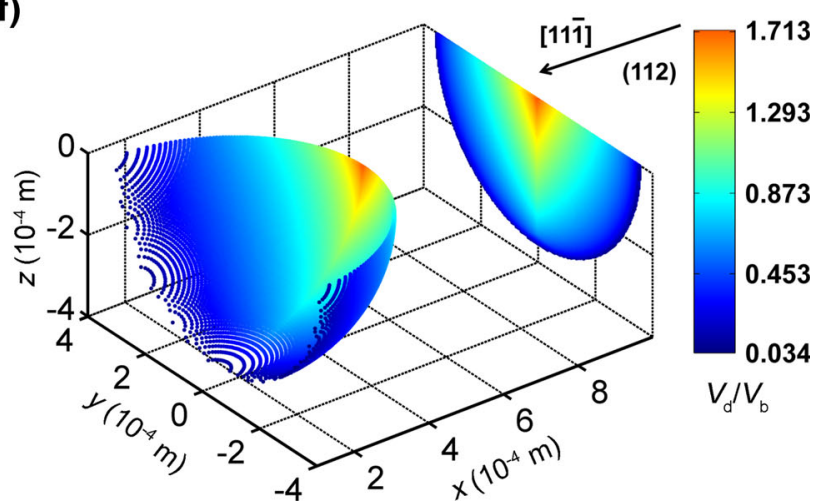

Fig. 5 Calculated dendrite growth velocity along preferred orientation $V_{\mathrm{d}}$ for various orientations: a $[100] /(001) ; \mathbf{b}[210] /(001)$; c $[110] /(001)$; d $[100] /(011) ; \mathbf{e}[0 \overline{1} 1] /(011) ; \mathbf{f}[11 \overline{1}] /(112)$ 
Table 3 Area fraction in the cross section of $V_{\mathrm{d}}$

\begin{tabular}{|c|c|c|c|c|c|c|}
\hline & $\begin{array}{l}{[100] /(001)} \\
(\%)\end{array}$ & $\begin{array}{l}{[210] /} \\
(001)(\%)\end{array}$ & $\begin{array}{l}{[110] /} \\
(001)(\%)\end{array}$ & $\begin{array}{l}{[100] /} \\
(011)(\%)\end{array}$ & $\begin{array}{l}{[0 \overline{1} 1] /} \\
(011)(\%)\end{array}$ & $\begin{array}{l}{[11 \overline{1}] /} \\
(112)(\%)\end{array}$ \\
\hline$V_{\mathrm{d}} / V_{\mathrm{b}} \leq 0.35$ & 11.20 & 10.51 & 10.60 & 11.22 & 10.60 & 11.31 \\
\hline $0.35<V_{\mathrm{d}} / V_{\mathrm{b}} \leq 0.70$ & 22.60 & 28.92 & 32.11 & 22.61 & 32.11 & 35.68 \\
\hline $0.70<V_{\mathrm{d}} / V_{\mathrm{b}} \leq 1.00$ & 66.21 & 34.80 & 31.26 & 66.17 & 31.26 & 30.76 \\
\hline$V_{\mathrm{d}} / V_{\mathrm{b}}>1.00$ & 0.00 & 25.77 & 26.03 & 0.00 & 26.03 & 22.25 \\
\hline
\end{tabular}

orientations are different. With the calculated values of $G_{\mathrm{d}}$ and $V_{\mathrm{d}}$, the tendency of stray grains formation was defined.

\subsection{Distribution of $\Phi$}

The $\Phi$ of each grid point for different orientations was calculated and the distribution of $\Phi$ is plotted in Fig. 6. In the present study, the microstructure was assumed to be fully columnar if $\Phi<0.66 \%$ according to Ref. [16], and the area where stray grain does not exist is colored with sky blue in Fig. 6.

In the same position and thermal conditions, $\Phi_{\mathrm{B}}$ may be different due to the different orientations. Figure $6 a, c, d$ indicates that stray grain easily forms at the joint area where dendrites of different directions grow together. In Fig. 6b, the area of high $\Phi$ exists at the meeting place of the [100] and [010] dendrites. In Fig. 6e, the area of high $\Phi$ appears at the surface where $x$ is bigger, while in Fig. 6f, it is at the place where $x$ is bigger and the absolute value of $y$, $z$ is smaller.

Area fraction of $\Phi$ in the cross section for different orientations is given in Table 4. In the conditions of [100]/ (001), [210]/(001), [100]/(011), a few area fraction of $\Phi$ is bigger than $8 \%$. The area fraction of $\Phi>4 \%$ in the [100]/ (001) and [100]/(011) conditions is apparently smaller than that in other conditions. On the plane of (001), compared with the scanning direction [100] and [210], the singlecrystal fraction of [110] rises about $4 \%$. For the direction [100] on (001) plane and [100] on (011), the single-crystal fraction is close. In $[11 \overline{1}] /(112)$, the areal fraction of $\Phi \leq 0.66 \%$ or $\Phi>8 \%$ is apparently bigger than other conditions. From Sects. 3.3 and 3.4, there are larger area with low $V_{\mathrm{d}}$ and high $G_{\mathrm{d}}$ and larger area with high $V_{\mathrm{d}}$ and low $G_{\mathrm{d}}$ in the direction [11 $\left.\overline{1}\right]$ on (112) plane. Consequently, the fraction of single crystal in $[11 \overline{1}] /(112)$ is far more than that in other conditions, and the area fraction of the section that contains a high fraction of stray grains is bigger than that in other conditions. From Eq. (10), with the increasing $V$, the value of $S$ decreases and $\Phi$ increases. With the increasing $G, S$ increases and $\Phi$ decreases. Combined with Figs. 4, 5, and 6, $\Phi$ is smaller while $V$ is smaller or $G$ is bigger. $\Phi$ is bigger while $V$ is bigger or $G$ is smaller.
In short, the distribution and areal fraction of $\Phi$ are affected by substrate orientations.

\section{Discussion}

\subsection{Calculation of Temperature Distribution}

Keyhole and conduction laser modes are two main operational regimes in laser welding [18-20], and the main difference between these two modes is the power density used. According to the work of Gaumann et al. [16], in order to ensure high temperature gradient, keyhole mode of laser cladding should be avoided for repairing single crystals.

The interaction between a laser beam and the irradiated material is a complex physical phenomenon. There are a fall in the reflectivity and an increase in the absorptivity of the laser with a rise in temperature of metals, as seen in Refs. [19, 21]. Due to the lack of basic experimental parameters, such as the laser absorptivity of various materials and thermal conductivity in different temperatures, many numerical models [19, 22, 23] developed to describe the weld pool cannot work well.

Without focusing on welding conditions (laser beam diameter, weld speed, power, laser absorptivity) and neglecting the diameter of laser beam, a simple 3D Rosenthal solution for a moving point source [19, 24] was used to determine the thermal conditions for conduction laser mode.

The calculated results (for $P=100 \mathrm{~W}, V_{\mathrm{b}}=0.01 \mathrm{~m} / \mathrm{s}$, $T_{0}=300 \mathrm{~K}$ ) apply to experimental cases when laser beam diameter is smaller than $0.25 \mathrm{~mm}$ (the model neglecting the diameter of laser beam), the laser power is given in ranges of $650-850 \mathrm{~W}$ (the absorptivity is influenced by the roughness of surface), and the size of substrate should be bigger than $5 \mathrm{~mm} \times 10 \mathrm{~mm} \times 20 \mathrm{~mm}$ to avoid quickly rise of substrate temperature.

Besides the Rosenthal solution, in the process of repairing thin-walled single-crystal parts, the temperature distribution can be obtained by this model [25]. And other temperature distribution models have been given in Refs. 
(a)

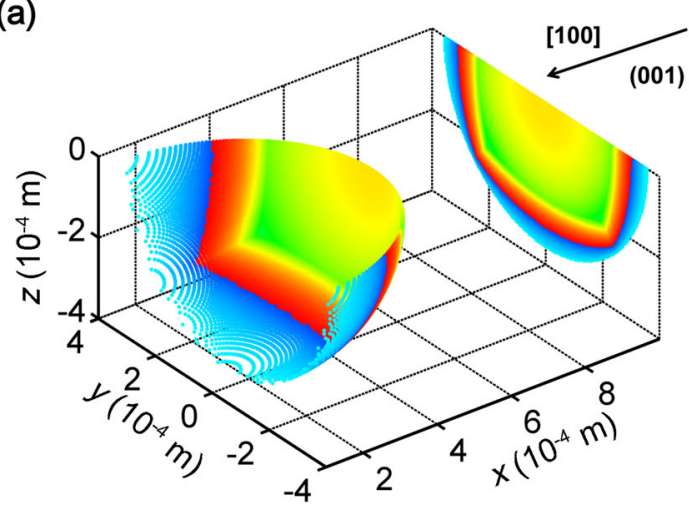

(c)

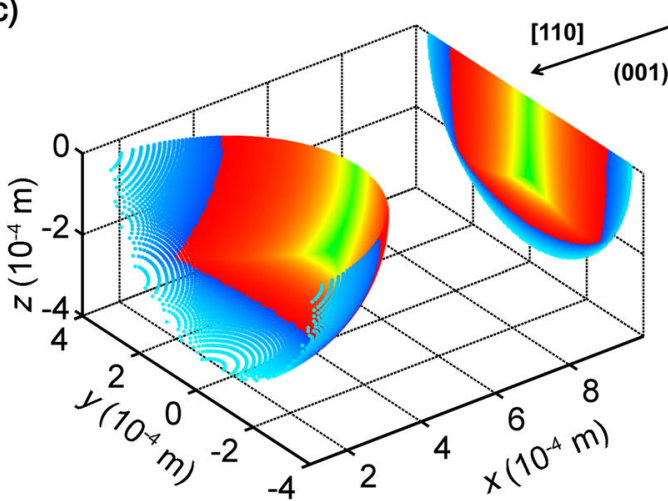

(e)
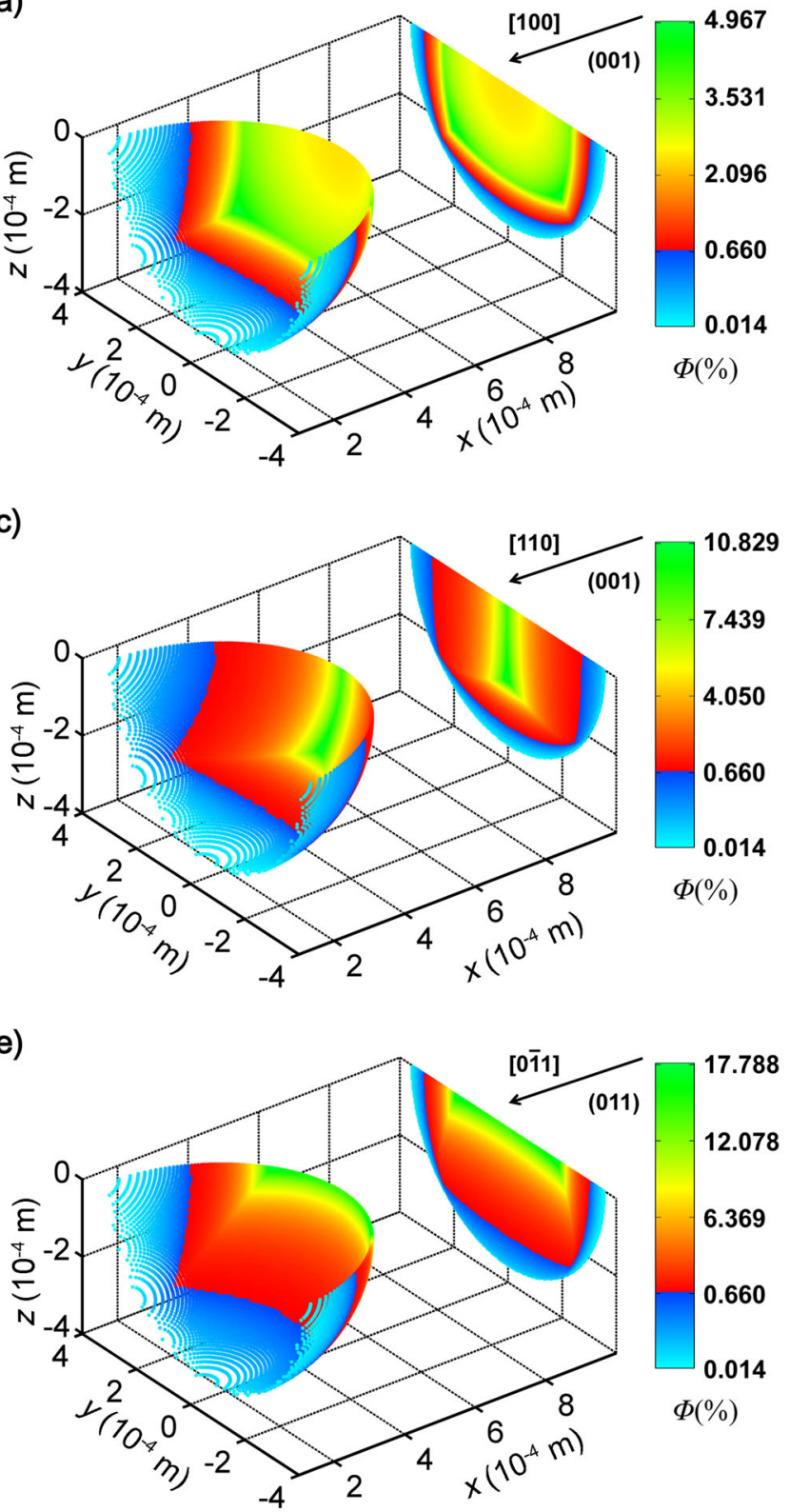

(b)

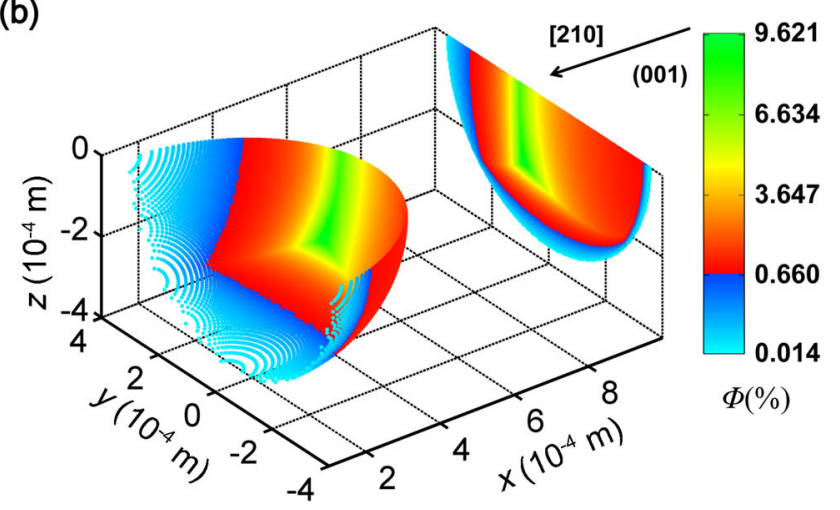

(d)

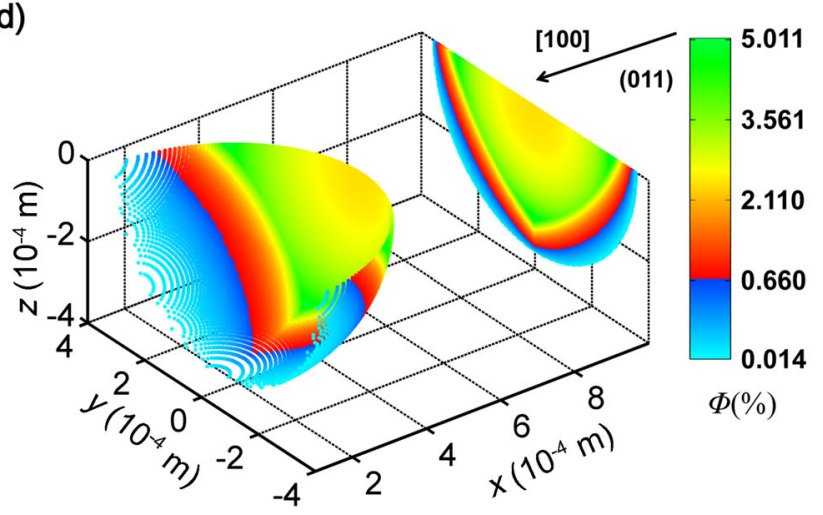

(f)

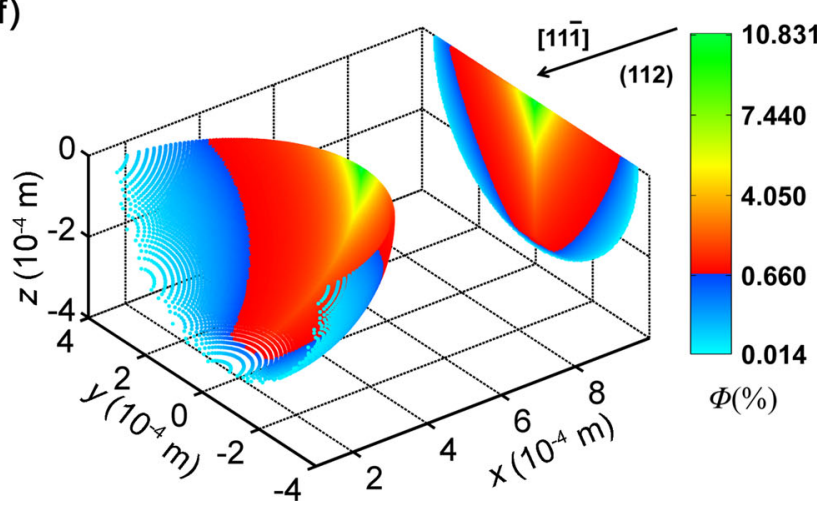

Fig. 6 Calculated areal fraction of stray grains $\Phi$ for various orientations; the area without SG is colored with sky blue: a [100]/(001); b [210]/ (001); c $[110] /(001) ; \mathbf{d}[100] /(011) ; \mathbf{e}[0 \overline{1} 1] /(011) ; \mathbf{f}[11 \overline{1}] /(112)$

Table 4 Areal fraction in the cross section of $\Phi$

\begin{tabular}{|c|c|c|c|c|c|c|}
\hline & {$[100] /(001)(\%)$} & {$[210] /(001)(\%)$} & {$[110] /(001)(\%)$} & {$[100] /(011)(\%)$} & {$[0 \overline{1} 1] /(011)(\%)$} & {$[11 \overline{1}] /(112)(\%)$} \\
\hline$\Phi \leq 0.66 \%$ & 19.98 & 19.76 & 24.12 & 19.97 & 24.12 & 29.38 \\
\hline $0.66 \%<\Phi \leq 4 \%$ & 77.00 & 63.70 & 57.51 & 77.00 & 57.51 & 55.76 \\
\hline $4 \%<\Phi \leq 8 \%$ & 3.02 & 15.71 & 15.37 & 3.03 & 15.36 & 11.00 \\
\hline$\Phi>8 \%$ & 0.00 & 0.83 & 2.99 & 0.00 & 3.01 & 3.85 \\
\hline
\end{tabular}


$[19,25,26]$. In the same way, the areal fraction and distribution of stray grains can be predicted in the same method set out in this work. Additionally, temperature distribution modeling considering powder feeding is yet to be solved.

\subsection{Dendrite Growth Direction and Application}

In Ref. [11], once $G_{x}, G_{y}$ and $G_{z}$ are known, the normal orientation of the solidification front can be identified since it is parallel to the total thermal gradient vector. The values of the misorientation angle $\Psi$ between the normal front and a particular dendrite growth direction can then be determined. The thermal gradient in the dendrite growth direction $\left(G_{\mathrm{d}}\right)$ is given by: $G_{\mathrm{d}}=\left|G_{x}\right| \cos \Psi$. However, computing methods cannot work well when it is used to calculate tens of thousands grid points in the solidification front. In Sect. 2.2, in order to ensure the automatic detecting of dendrite growth direction by computing program, all the parameters were vectorized and the angle $\Psi$ was abandoned in this work.

This work introduces the application of dendrite growth direction. Apparently, the areal fraction of dendrite growing along [001] will change with the change of laser power or scanning velocity. Therefore, the calculation can be utilized to predict the areal fraction of dendrites growing along [001]. For the epitaxial deposition of MCrAlY coatings [27], the dendrites growing along [001] are more required.

As for repairing single parts or cladding of single crystals, the dendrites growing along [100] or [010] may be harmful to the mechanical property (remaining to be proved). But, with the prediction of dendrite growth direction, the dendrites growing along [100] or [010] can be remelted exactly during the next layer printing. Finally, the dendrites of cladding section can get the same growth orientation of [001].

\subsection{Analysis of $G_{\mathrm{d}}$ and $V_{\mathrm{d}}$ and Stray Grain Distribution}

From Sect. 2.2, for a same point, $G_{\mathrm{d}}=\operatorname{maximum}\left(\left|G_{100}\right|\right.$, $\left.\left|G_{010}\right|, \quad\left|G_{001}\right|\right), \quad G_{\mathrm{sl}}=\left(\left|G_{100}\right|^{2}+\left|G_{010}\right|^{2}+\left|G_{001}\right|^{2}\right)^{0.5}$. So, $G_{\mathrm{d}} \leq G_{\mathrm{sl}},\left(G_{\mathrm{d}}\right)_{\max } \leq G_{\mathrm{sl}}$. $\left(G_{\mathrm{d}}\right)_{\min }=G_{\mathrm{sl}} / 3^{0.5}$ while $\left|G_{100}\right|=$ $\left|G_{010}\right|=\left|G_{001}\right| .\left(V_{\mathrm{d}}\right)_{\max }=V_{\mathrm{b}} \cdot\left|G_{x}\right| / G_{\mathrm{d}} \leq V_{\mathrm{b}} \cdot G_{\mathrm{s}} / G_{\mathrm{d}} \leq V_{\mathrm{b}} \cdot G_{\mathrm{sl}} \mid$ $\left(G_{\mathrm{d}}\right)_{\min } \leq 3^{0.5}$. In a mathematical sense, $\left(V_{\mathrm{d}}\right)_{\max } \approx 1.73 V_{\mathrm{b}}$. However, the number of elements used in numerical computing is insufficient to render $\left(V_{\mathrm{d}}\right)_{\max }$ close to $1.73 V_{\mathrm{b}}$.

Unlike the results in Ref. [11], the orientation has an important effect on the areal fraction of stray grains given in Table 4. The reason for the difference is that the solidification front of weld pool was divided into only 10-20 sections in Ref. [11]. Compared with the recent work [13], Fig. $4\left(\mathrm{a}, \xi_{x}=0^{\circ}\right),\left(\mathrm{a}, \xi_{x}=45^{\circ}\right),\left(\mathrm{b}, \xi_{y}=45^{\circ}\right)$ and (c, $\left.\xi_{z}=45^{\circ}\right)$ in Ref. [13] for $\xi_{x}=0^{\circ}, \xi_{x}=45^{\circ}, \xi_{y}=45^{\circ}$ and $\xi_{z}=45^{\circ}$ is explained by Fig. $6 \mathrm{a}, \mathrm{c}, \mathrm{d}$, e in this paper, respectively. Apparently, the figures are clearer and the calculation is more precise in this work. And the complex orientation cannot be modeled well by Ref. [13].

In the same way, stray grains distribution for other thermal conditions can be predicted. The most favorable location for stray grain formation can be predicted before experiments. With the prediction, it will not be difficult to select a proper processing parameter for single-crystal laser welding or repairing.

\subsection{Extending Discussion}

In Ref. [16], the nuclei density, $N_{0}$, seems to be constant and characteristic for a given alloy. Revised values of $N_{0}$, $a$ and $n$ for CMSX-4 have been proposed in Ref. [12], but the values of the constants should be revised with a large number of remelting experiments. During laser cladding, weld metal grows epitaxially from the substrate superalloy, and the crystallographic orientation of the substrate and weld metals will be consistent. If there are any stray grains cladded before, the stray grains will also grow epitaxially. Competitive grain growth in directional solidification has been studied by Zhou et al. [28]. Besides, the research of competitive grain growth in the laser cladding would be useful to control the stray grain growth. In Fig. 3a, d, there are many grains growing along the [100] direction. If there are any stray grains close to the [100] orientation, it may grow epitaxially and affect the measurement accuracy of $N_{0}, a$ and $n$. In Ref. [29], it is worth noting that one of stray grain formation mechanisms is the bending or detachment of side arms during extension of secondary arms in directional solidification. As for the influence of fluid flow in the weld pool, it is beyond the scope of this article.

\section{Conclusions}

Effects of substrate crystallographic orientations on stray grain distribution are investigated, and a heat transfer code has been proposed to simulate the weld pool size and shape. With the vectorization of experimental parameters, the model handles complex orientation very well and the writing of computing program can be easier. Calculating results indicate that substrate crystallographic orientation affects the dendrites growth direction, distribution of thermal gradient along dendrite growth direction and dendrite growth velocity and further affects the distribution of stray grains. The stray grains fraction in the $[11 \overline{1}]$ direction on (112) plane is significantly less than other conditions. In summary, substrate crystallographic orientations have some effects on the overall tendency or local variation of stray grains formation. 
Acknowledgments This work was financially supported by the National Natural Science Foundation of China (Nos. 51401210 and 51271186) and the National High Technology Research and Development Program of China (No. 2014AA041701).

\section{References}

[1] Z.D. Fan, D. Wang, L.H. Lou, Acta Metall. Sin. (Engl. Lett.) 28, $152(2015)$

[2] Z.X. Shi, S.Z. Liu, J.R. Li, Acta Metall. Sin. (Engl. Lett.) 28, 1278 (2015)

[3] M. Gaumann, S. Henry, F. Cleton, J.D. Wagniere, W. Kurz, Mater. Sci. Eng., A 271, 232 (1999)

[4] J.D. Hunt, Mater. Sci. Eng. 65, 75 (1984)

[5] M. Gaumann, R. Trivedi, W. Kurz, Mater. Sci. Eng., A 226, 763 (1997)

[6] M. Rappaz, S.A. David, J.M. Vitek, L.A. Boatner, Metall. Trans. A 20, 1125 (1989)

[7] S.A. David, J.M. Vitek, M. Rappaz, L.A. Boatner, Metall. Trans. A 21, 1753 (1990)

[8] M. Rappaz, S.A. David, J.M. Vitek, L.A. Boatner, Metall. Trans. A 21, 1767 (1990)

[9] W.P. Liu, J.N. DuPont, Acta Mater. 52, 4833 (2004)

[10] W.P. Liu, J.N. DuPont, Acta Mater. 53, 1545 (2005)

[11] J.M. Vitek, Acta Mater. 53, 53 (2005)

[12] T.D. Anderson, J.N. DuPont, T. DebRoy, Acta Mater. 58, 1441 (2010)
[13] L. Wang, N. Wang, W.J. Yao, Y.P. Zheng, Acta Mater. 88, 283 (2015)

[14] J.W. Park, S.S. Babu, J.M. Vitek, E.A. Kenik, S.A. David, J. Appl. Phys. 94, 4203 (2003)

[15] J.W. Park, J.M. Vitek, S.S. Babu, S.A. David, Sci. Technol. Weld. 9, 472 (2004)

[16] M. Gaumann, C. Bezencon, P. Canalis, W. Kurz, Acta Mater. 49, 1051 (2001)

[17] D. Rosenthal, Trans. ASME 48, 849 (1946)

[18] J.F. Ready, D.F. Farson, LIA Handbook of Laser Materials Processing (Springer, Berlin, 2001), pp. 307-424

[19] W.M. Steen, J. Mazumder, Laser Materials Processing, 4th edn. (Springer, London, 2010), pp. 199-294

[20] S. Katayama, Handbook of Laser Welding Technologies (Woodhead Publishing Limited, Cambridge, 2013), pp. 139-162

[21] G.G. Gladush, I. Smurov, Physics of Laser Materials Processing (Springer, Berlin, 2011), pp. 9-19

[22] H.E. Cline, T.R. Anthony, J. Appl. Phys. 48, 3895 (1977)

[23] M. Davis, P. Kapadia, J. Dowden, W.M. Steen, C.H.G. Courtney, J. Phys. D 19, 1981 (1986)

[24] D. Rosenthal, Weld. J. 20, 220 (1941)

[25] E. Kannatey-Asibu, Principles of Laser Materials Processing (Hoboken, 2009), pp. 228-280

[26] J.M. Dowden, Mathematics of Thermal Modeling: An Introduction to the Theory of Laser Material Processing (Chapman \& Hall/CRC, Boca Raton, 2001)

[27] C. Bezencon, A. Schnell, W. Kurz, Scr. Mater. 49, 705 (2003)

[28] Y.Z. Zhou, A. Volek, N.R. Green, Acta Mater. 56, 2631 (2008)

[29] Y.Z. Zhou, Scr. Mater. 65, 281 (2011) 